\title{
Psicanálise e Gênero: tão íntimo, tão estranho
}

\author{
Psychoanalysis and Gender: So Intimate, So Strange
}

Gustavo Angeli (i) 0000-0003-1732-1081

Vinicius da Rocha Barros ${ }^{1}$ (D) 0000-0002-8416-2722

'Universidade Federal de Santa Catarina, Programa de Pós-Graduação em Psicologia, Florianópolis, SC, Brasil. 88040-900 - ppgpsi@contato.ufsc.br

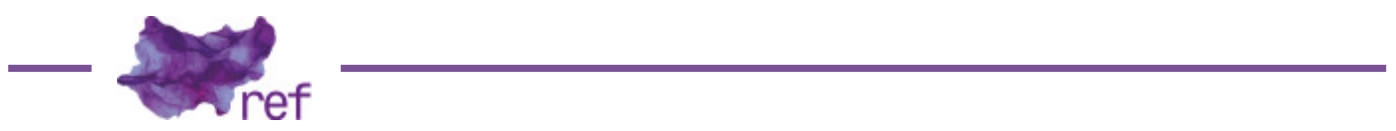

FRANÇOIA, Carla; PORCHAT, Patrícia; CORSETTO, Patrizia (Orgs.).

Psicanálise e Gênero: narrativas feministas e queer no Brasil e na Argentina.

Curitiba: Calligraphie, 2018.

A coletânea Psicanálise e Gênero: Narrativas feministas e queer no Brasil e na Argentina (2018), organizada por Carla Françoia, Patrícia Porchat e Patrizia Corsetto, que integra a série "Corpo, sexualidade e tecnologia" da Caligraphie Editora, reúne artigos e entrevistas de/com psicanalistas, teóricas dos estudos feministas, de gênero e queer.

Na primeira da parte da coletânea encontramos um compilado de diálogos que convidam a pensar, de forma interdisciplinar, interrogações e questões afloradas pelos novos tempos, sujeitos e demandas. Nesse sentido, visam ao fortalecimento dos diálogos dos estudos de gênero na psicanálise, para além de concepções clássicas da teoria psicanalíica.

Françoia (2018) escreve "Era uma vez no Brasil", retratando a história do seu primeiro paciente interessado na "cirurgia de mudança de sexo" (Carla Regina FRANÇOIA, 2018b, p. 13). Tomada pela novidade, ela escuta o seu sofrimento, que não reconhecia aquele corpo como seu. "Um desconhecido de si mesmo, tão íntimo, tão estranho." (FRANÇOIA, 2018b, p. 13). Ao compartilhar com seus pares suas descobertas teóricas que auxiliaram na atuação clínica, encontra resistência, pois, segundo ela: "Se não está em Lacan ou em Freud ou em seus comentadores tradicionais, não existe, não é teoria válida, está errado. Foi o início de uma jornada solitária" (FRANÇOIA, 2018b, p. 14).

No capítulo seguinte, Elizabeth Zambrano (2018) propõe uma desacomodação de valores naturalizados a partir do diálogo entre psicanálise e antropologia, envolvendo não apenas sexualidade, família, o conceito de normalidade, gênero, como também a psicanálise, que tem uma história e está sujeita a transformações e releituras. Zambrano (2018) acredita que a falta de discussões a partir de autorias críticas dentro dos currículos da formação conduz a ideias normativas e patriarcais, à naturalização da diferença sexual, contribuindo para a sedimentação de verdades que sustentam patologias, bem como desconsideram as novas configurações de família, construções identitárias e práticas sexuais não convencionais.

Em "Barulhos de gênero", Patrícia Porchat (2018a) questiona as possibilidades de pesquisar o campo das homossexualidades, sem considerar de início as práticas homossexuais como perversão ou patologia. A psicanálise se transforma na medida que as vozes que circulam nas ruas e quem as escuta é convocada/o a problematizar discussões em torno do encobrimento da diversidade das sexualidades e do gênero. A autora demarca a urgência de uma escuta para 
além da patologização e aponta o crescente interesse de psicanalistas pelas questões relacionadas ao gênero mesmo com barulhos e ruídos.

Vera laconelli (2018) interroga o lugar da mulher na psicanálise. Apresenta os desdobramentos dessa abordagem e propõe uma inversão da mulher falada para a mulher que fala na história da psicanálise, entrelaçada ao movimento feminista para criar aberturas de fala às mulheres. Se por um lado há a escuta das histéricas e a inauguração da psicanálise; por outro, ainda há uma patologização em relação às mulheres, um fazer falar e calar ao mesmo tempo. Conforme aponta: "A psicanálise começa, quando uma mulher manda seu médico calar-se para que a escute" (IACONELLI, 2018, p. 45)

Ana Laura Prates (2018), por sua vez, problematiza o encontro entre uma sexóloga, que explica a relação neurológica do orgasmo apoiado nos estímulos dos órgãos sexuais para um grupo de adolescentes trans, que a interpelam: "E o cu?" (PRATES, 2018, p. 51). A autora critica o discurso científico que tanto firma mapas anatômicos a partir das funcionalidades e dos respaldados genéticos, quanto invisibiliza a transexualidade e a intersexualidade.

Em "Da letra da mulher à reescritura da psicanálise", Carla Françoia (2018a) aborda contextos históricos e processos políticos que sustentam a teoria psicanalítica em um discurso hegemônico frente à diferença sexual. Aponta que no início da construção da psicanálise, Freud deparou-se com "mulheres que apresentavam uma loucura do sexo, as histéricas, Lacan também parte da loucura feminina, questionando a organização do desejo na construção da personalidade" (FRANÇOIA, 2018a, p. 64). Essa loucura feminina estava respaldada pela ciência e pela psicanálise, o que reforçou "no imaginário social da dominação do feminino, baseandose no binarismo natural - masculino/feminino -, uma tecnologia do sexo, sendo o falo/pênis o elemento organizador dessa verdade" (FRANÇOIA, 2018a, p. 64).

No capítulo "Gênero e epistemologia psicanalíica", Pedro Ambra (2018), ao apontar momentos em que Freud e Lacan desenlaçam repetidas vezes "a insularidade da Psicanálise não apenas estabelecendo diálogo, mas refundando a própria Psicanálise a partir de problemas, conceitos e racionalidades importadas seja do campo social, seja de outros saberes" (AMBRA, 2018 , p. 89), o autor problematiza a expressão "sociologização da psicanálise" (AMBRA, 2018, p. 82), usada como defesa que parte da interpretação referente à advertência freudiana sobre a psicanálise não se tornar uma visão de mundo. Dessa forma, a entrada da psicanálise nos estudos de gênero para repensar sua própria teoria da diferença sexual seria indesejada. Essa defesa narcísica aponta para o ideal de uma "psicanálise pura" ferindo a epistemologia psicanalítica na qual "sua verdade é indissociável da inquietude de sua produção." (AMBRA, 2018, p. 81). Para ele, Freud e Lacan deixaram como legado "uma prática de humildade da teoria em face à emergência da alteridade" (AMBRA, 2018, p. 90) e se sustentarmos uma suposta pureza teórica, "contraditoriamente, deixaremos de fazer Psicanálise" (AMBRA, 2018, p. 90).

Susana Muszkat (2018), em "Desamparo e violência de gênero: uma formulação", discute o entendimento da violência como natural do sexo biológico e masculino, a naturalização das práticas violentas como um impedimento a uma intervenção, assim como a legitimação da ałuação e continuidade da violência. Conforme aponta, a fixação em papéis de gênero aprisiona os sujeitos em um ideal e impede questionamentos ou transformações. A autora propõe um processo de desconstrução de paradigmas e modelos fixos de funcionamento. Uma saída de concepções maniqueístas da violência para o entendimento de sua complexidade, objetivando problematizar os ciclos de violência que se mantêm a partir das políticas públicas do combate à violência.

A segunda parte da coletânea é composta de entrevistas realizadas por Patrícia Porchat (2018b) com psicanalistas argentinas/os e uma psicanalista chinela. Apresentamos, a seguir, alguns recortes e passagens das entrevistas que demarcam as dificuldades, resistências e 0 percurso singular de cada entrevistada/o ao propor um entrelaçamento entre a psicanálise e os estudos de gênero. Essas experiências (de)marcam a desconstrução e a transformação que os estudos de gênero e a diversidade sexual possibilitaram, dentro e fora da psicanálise.

Por esse viés, Ana María Fernández relata para a entrevistadora sua passagem pela ditadura argentina e a implementação dos estudos sobre a mulher dentro de um movimento de resistência que questionava a opressão social do Estado, da psicanálise, das questões de gênero dentro da teoria psicanalíica. Para Fernández, a psicanálise seria instrumento de escuta das latências coletivas.

Já Irene Meler, em sua fala, alega que a psicanálise precisa das teorias de gênero e dos estudos interdisciplinares para contextualizar aquilo que está dito sobre o feminino, melhorando a compreensão do psiquismo e da subjetividade. Meler entende que a resistência de psicanalistas frente às formulações de gênero está na base da formação médica e psicológica que vê a profissão como lucrativa, reproduzindo a sociedade capitalista, sem o interesse de questionamentos.

Por sua vez, Juan Carlos Volnovich ressalta que os estudos de gênero dentro da psicanálise argentina não estavam associados às sociedades psicanalíticas, que incorporaram as discussões de gênero de forma precária. O psicanalista reconhece que os estudos do gênero permitiram escutar a relação dos homens com a prostituição, consumo do sexo - e outros pontos cegos anulados pela cumplicidade de gênero. 
Mabel Burin iniciou com crianças seus estudos no campo da psicanálise. Orientada por sua tutora, La negra Aberastury, aprendeu a escutar as mulheres da década de 1960 para além das demandas maternas e reconhecer, apoiada nisso, duas fontes de mal estar: a sexualidade na conjugalidade e a interrupção dos estudos e da profissão. Para Burin, as perspectivas dos estudos de gênero propõem uma novidade teórica: ampliar o repertório desejante da mulher, pois entende que as condições de saúde mental ultrapassam a premissa freudiana: amar e trabalhar.

Já Eva Giberti afirma, em sua entrevista, a importância de uma revisão dos textos freudianos a partir dos estudos feministas e não mais do patriarcado, para avançar nos estudos e na escuta das mulheres. Na opinião da psicanalista, uma releitura cuidadosa permitirá criar diálogos entre a psicanálise e os estudos de gênero.

Débora Tajer e Pilar Errázuriz são entrevistadas em conjunto. Apresentam distinções de percurso, encontros e diálogos nos estudos. Uma psicanálise com perspectiva de gênero, para Tajer, é dialogar com o social, com o político e com o momento histórico, tal como Freud trabalhava. Faz-se necessário identificar os núcleos duros da psicanálise tradicional e considerar o sustento da lógica de poder - ao manter a heterossexualidade como sexualidade desejável e não reconhecer as assimetrias de gênero e de classe.

A psicanalista Errázuriz, única psicanalista chilena nesta coletânea, relata ter sido introduzida aos estudos de gênero pelo encontro com exiladas/os argentinas/os na Espanha durante o período ditatorial, que lhe apresentaram referências e obras sobre o tema. Na entrevista, conta que a psicanálise chilena se diferencia da psicanálise argentina, pois "é muito menor, e muito paralisada, e não por ser ortodoxa, mas por uma espécie de preconceito. Há um preconceito com o gênero, porque o relacionam ao feminismo" (Pilar ERRÁZURIZ, 2018, p. 183).

Por fim, Carlos Alberto Barzani descreve a homofobia em seus primeiros anos como estudante de psicologia e psicanálise, a tentativa de encontrar outros textos e autorias sobre a sexualidade para além da perversão e da patologia. Ressalta a participação do social e da cultura na psicanálise e a dificuldade dos psicanalistas em escutar o social em seus divãs.

A busca por dissoluções, frente à querela da sexualidade, em especial da sexualidade feminina, das feminilidades e narrativas sobre a mulher, convocou as organizadoras a pesquisar, produzir e propor um diálogo franco entre psicanálise, teorias de gênero, feministas e queer. Uma releitura que visa a despatologização e a desconstrução de preconceitos dentro da própria psicanálise, o convite à elaboração de saberes e a escuta das singularidades que não se encontram dissociadas do social. Os textos e entrevistas que integram a coletânea mostram que se faz necessário uma travessia pelas fronteiras dos países, fronteiras teóricas e epistemológicas, uma travessia no silenciamento dentro do movimento psicanalítico das inquietações que os estudos de gênero provocam e interpelam sem se deixar normatizar; pelo contrário, demarcando possibilidades, fronteiras e atravessamentos entre o íntimo e o estranho, que habitam em nós e na teoria.

\section{Referências}

AMBRA, Pedro. "Gênero e epistemologia psicanalítica". In: FRANÇOIA, Carla; PORCHAT, Patrícia; CORSETTO, Patrizia (Orgs.). Psicanálise e Gênero: narrativas feministas e queer no Brasil e na Argentina. Curitiba: Calligraphie, 2018. p. 81-94.

ERRÁZURIZ, Pilar. "Débora Tajer e Pilar Errázuriz". [Entrevista concedida a] Patricia Porchat. In: FRANÇOIA, Carla; PORCHAT, Patrícia; CORSETTO, Patrizia (Orgs.). Psicanálise e Gênero: narrativas feministas e queer no Brasil e na Argentina. Curitiba: Calligraphie, 2018. p. 177-185.

FRANÇOIA, Carla; PORCHAT, Patrícia; CORSETTO, Patrizia (Orgs.). Psicanálise e Gênero: narrativas feministas e queer no Brasil e na Argentina. Curitiba: Calligraphie, 2018.

FRANÇOIA, Carla Regina. "Da letra da mulher à reescritura da psicanálise". In: FRANÇOIA, Carla; PORCHAT, Patrícia; CORSETTO, Patrizia (Orgs.). Psicanálise e Gênero: narrativas feministas e queer no Brasil e na Argentina. Curitiba: Calligraphie, 2018a. p. 63-80.

FRANÇOIA, Carla Regina. "Era uma vez no Brasil". In: FRANÇOIA, Carla; PORCHAT, Patrícia; CORSETTO, Patrizia (Orgs.). Psicanálise e Gênero: narrativas feministas e queer no Brasil e na Argentina. Curitiba: Calligraphie, 2018b. p. 13-16.

IACONELLI, Vera. "Mulher falada". In: FRANÇOIA, Carla; PORCHAT, Patrícia; CORSETTO, Patrizia (Orgs.). Psicanálise e Gênero: narrativas feministas e queer no Brasil e na Argentina. Curitiba: Calligraphie, 2018. p. 45-50.

PORCHAT, Patrícia. "Barulhos de gênero". In: FRANÇOIA, Carla; PORCHAT, Patrícia; CORSETTO, Patrizia (Orgs.). Psicanálise e Gênero: narrativas feministas e queer no Brasil e na Argentina. Curitiba: Calligraphie, 2018a. p. 35-44. 
PORCHAT, Patrícia. "Era uma vez na América Latina". In: FRANÇOIA, Carla; PORCHAT, Patrícia; CORSETTO, Patrizia (Orgs.). Psicanálise e Gênero: narrativas feministas e queer no Brasil e na Argentina. Curitiba: Calligraphie, 2018b. p. 115-194.

PRATES, Ana Laura. "Gozar de boneca: mapas anatômicos e genéticos". In: FRANÇOIA, Carla; PORCHAT, Patrícia; CORSETTO, Patrizia (Orgs.). Psicanálise e Gênero: narrativas feministas e queer no Brasil e na Argentina. Curitiba: Calligraphie, 2018. p. 51-62.

MUSZKAT, Susana. "Desamparo e violência de gênero: uma formulação". In: FRANÇOIA, Carla; PORCHAT, Patrícia; CORSETTO, Patrizia (Orgs.). Psicanálise e Gênero: narrativas feministas e queer no Brasil e na Argentina. Curitiba: Calligraphie, 2018. p. 95-112.

ZAMBRANO, Elizabeth. "Diálogos de uma psicanalista com a Antropologia: um relato pessoal". In: FRANÇOIA, Carla; PORCHAT, Patrícia; CORSETTO, Patrizia (Orgs.). Psicanálise e Gênero: narrativas feministas e queer no Brasil e na Argentina. Curitiba: Calligraphie, 2018. p. 17-34.

Gustavo Angeli (gustavooangeli@gmail.com) é psicólogo pela Universidade Regional de Blumenau, doutorando em Psicologia pela Universidade Federal de Santa Catarina na área de concentração Psicologia Social e Cultura e linha de pesquisa Processos de Subjetivação, Gênero e Diversidades, mestre em Psicologia pela Universidade Estadual de Maringá. Docente do Curso de Psicologia no Centro Universitário de Brusque - UNIFEBE.

Vinicius da Rocha Barros (viniciusrbarros@gmail.com) é psicanalista e psicólogo pela Universidade Regional de Blumenau, mestrando em Psicologia pela Universidade Federal de Santa Catarina na área de concentração Psicologia Social e Cultura e linha de pesquisa Processos de Subjetivação, Gênero e Diversidades, com pós-graduação em Psicologia Clínica na Abordagem Psicanalítica pela Pontifícia Universidade Católica do Paraná, PUC-PR.

\section{COMO CITAR ESSE ARTIGO DE ACORDO COM AS NORMAS DA REVISTA}

ANGELI, Gustavo; BARROS, Vinicius da Rocha. "Psicanálise e Gênero: tão íntimo, tão estranho". Revista Estudos Feministas, Florianópolis, v. 28, n. 3, e67688, 2020.

\section{CONTRIBUIÇÃO DE AUTORIA}

Os autores contribuíram igualmente na concepção e elaboração do manuscrito, redação, revisão e ajustes finais do trabalho.

\section{FINANCIAMENTO}

Não se aplica.

\section{CONSENTIMENTO DE USO DE IMAGEM}

Não se aplica.

\section{APROVAÇÃO DE COMITÊ DE ÉTICA EM PESQUISA}

Não se aplica.

\section{CONFLITO DE INTERESSES}

Não se aplica.

LICENÇA DE USO

Este artigo está licenciado sob a Licença Creative Commons CC-BY International. Com essa licença você pode compartilhar, adaptar, criar para qualquer fim, desde que atribua a autoria da obra.

\section{HISTÓRICO}

Recebida em 21/09/2019

Revisões requeridas em 13/01/2010

Aprovada em 23/02/2020 